\title{
Language in the Workplace Project and Workplace Communication for Skilled Migrants course at Victoria University of Wellington, New Zealand
}

\section{The context}

The School of Linguistics and Applied Language Studies (LALS) at Victoria University of Wellington conducts research and teaching in Linguistics, Applied Linguistics, Writing and Deaf Studies. It incorporates a Deaf Studies Research Unit, which undertakes research on topics relating to deaf people and their language in New Zealand, and the New Zealand Dictionary Centre, set up in partnership with Oxford University Press, which provides a base for research into New Zealand lexicography and aspects of language in New Zealand. It also incorporates an English Language Institute, which specialises in teaching English language courses and teacher education programmes. A particular strength of the School's makeup is the opportunity to engage in research which benefits and is benefited by both theoretical and practical approaches to issues in linguistics and applied linguistics. This report on research in progress describes one of a number of examples of the productive integration of language teaching and language research at LALS. We describe an ongoing research project that has developed organically over the past twelve years. The research first involved collecting and analysing authentic workplace interaction between native speakers, then made use of it in explicit instruction aimed at developing socio-pragmatic proficiency in the workplace among skilled migrants with English as an Additional Language (EAL), and is currently engaged in evaluating the results of the instruction, not only in the classroom, but also in workplaces where the migrants have been placed as interns.

\section{Language in the Workplace Project}

The broad aims of the Language in the Workplace Project (LWP) are: to identify the characteristics of effective communication between people in the workplace; diagnose possible causes of miscommunication; and explore possible applications of the findings for New Zealand workplaces. The first phase of this ongoing research entailed the development of an innovative methodology to collect authentic spoken interaction in a range of different New Zealand organisations. The key feature of the 
distinctive methodology is that, following a period of ethnographic observation, the participants themselves record their everyday workplace talk with as little interference from the research team as possible. Volunteers in each participating organisation record work-related meetings or discussion, as well as telephone calls and social conversations, and the project team videotapes a number of larger, more formal meetings from each workplace. To date, LWP has recorded approximately 1500 interactions from more than 500 participants in 22 workplaces, including government departments, factories, small businesses, and medical, corporate and IT organisations. The project team includes Janet Holmes (Project Director), Bernadette Vine (Corpus Manager) and Meredith Marra (Research Officer), along with associated researchers and workplace practitioners throughout New Zealand, and internationally, as well as a number of local research assistants. The team has analysed workplace directives, small talk, humour, gender, leadership, problem-solving, meetings, workplace culture, ethnicity, miscommunication and multicultural workplaces. The current phase of the LWP research focuses on the discourse of professional migrants in New Zealand workplaces. It takes the form of action research involving participants in a course that has been developed specifically to teach socio-pragmatic skills to professional migrants.

\section{Evaluating the effects of instruction in socio-pragmatic skills in workplace interaction}

\subsection{The context of the current action research project}

The current action research being undertaken by the LWP team involves the teacher and participants in a course designed to develop areas of socio-pragmatic proficiency which had been identified, on the basis of the analysis of earlier research data and interviews with employers, as crucial to successful integration in New Zealand workplaces. The participants are skilled migrants with EAL who have been unable to find work in their chosen profession in New Zealand. The Workplace Communication for Skilled Migrants course (henceforth 'Workplace Communication course') involves an in-class component as well as an internship at a New Zealand workplace $^{1}$. 
One important goal of the course is to develop awareness of characteristic features of communication in New Zealand workplaces. To this end, the data and analyses from the first phase of the LWP research have played an integral role in the development of the Workplace Communication course in at least two ways. Firstly, the LWP analyses have identified a range of strategies used by effective communicators to accomplish their transactional and relational goals, and these analyses provide a good deal of information about the communicative skills underlying effective relational talk. These research-based findings are some of the key target areas focused on in the Workplace Communication course. Secondly, the LWP corpus of authentic everyday interactions collected from professional workplaces provides an ideal resource for developing teaching and learning materials to assist migrant workers on the course.

With the first phase of the research fully integrated in the Workplace Communication course, the next challenge for the research team was to evaluate the effectiveness of this approach in developing socio-pragmatic proficiency for workplace interaction.

\subsection{The focus of the current action research project}

Inadequate communication skills are frequently identified as obstacles to hiring migrants, but these can often be more accurately attributed to sociolinguistic nuances in communicative styles. The first phase of LWP research demonstrated, for instance, the crucial importance of a range of relationally oriented communicative strategies in establishing good relationships at work. These include small talk and social talk, different types of humour in different workplaces, diverse ways of giving directives and making requests, and various ways of expressing negatively affective speech acts, such as refusals, complaints and disagreements in different communities of practice.

Although socio-pragmatic skills have been identified as important aspects of communicative competence in the workplace, little research has been undertaken to evaluate the effects of classroom-based support in developing these areas of language proficiency. The LWP action research project, presently in a pilot phase, tracks the development of migrants' socio-pragmatic skills not only as they progress through structured instruction, but also as they experience first-hand interactions in New Zealand workplaces. The analysis focuses on identifying changes in the migrants' 
socio-pragmatic proficiency in a range of aspects of relational discourse identified as crucial to effective workplace communication. The research project thus has two main elements: one classroom-based and one workplace-based.

\subsubsection{Classroom-based research}

The classroom-based element of the research project incorporates a number of different research tasks to evaluate student progress in acquiring the socio-pragmatic skills that are the focus of the Workplace Communication course. As part of the normal processes involved in participating in the course, data is gathered at the beginning, middle and end of the course on participants' spoken proficiency and ability to accurately interpret socio-pragmatic aspects of workplace talk, with a focus on requests and small talk.

Research in the classroom has increasingly focused on multiple methods for accessing socio-pragmatic competence, recognising that one method alone (e.g. discourse completion task or role play) is not able to provide an accurate picture of a participant's skills. The current research involves a wider range of methods. In the first week of the course, pre-instruction baseline data from participants is collected in the form of discourse completion tasks (DCTs), video-recorded role plays, and audiorecorded retrospective interviews. These research activities are repeated again halfway through the course and at the end of the course, to enable tracking individual participants' progress throughout the course. These data collection methods are also complemented by journal entries, observations, guided reflection tasks, and recorded group discussions. Oral presentations and reflections by participants in the final week enable assessing to what extent course participants themselves feel that the course has met their needs.

\subsubsection{Workplace-based research}

The second component of the research project evaluates the impact of classroom instruction on migrants' socio-pragmatic skills once they enter the workplace. This workplace-based element of the research is being undertaken in collaboration with workplaces offering temporary placements to professional migrants on the Workplace Communication course. First, employers willing to take placements are contacted and 
invited to participate in the research project, and each course participant is provided with an internal support person or mentor from within the organisation in which they have been placed. The next stage involves the collection of recorded data at the workplaces where course participants do their placement. This data collection follows the LWP methodological approach, described above, and in the present context involves collecting recorded data to establish workplace interactional norms prior to each course participant's commencement at the workplace, and collecting data from the course participant in the workplace at the start and at the end of the placement. The final stage involves collecting audio-recorded and written comments from employers, mentors, course participants and consultants, in relation to each participant's progress in communicating effectively at work, what they have learned, and any changes in perceptions of the course participant by other employees and the employer.

This workplace-based element of the research thus provides data that enables the research team to systematically document changes, if any, in professional migrant learners' ability to manage workplace interaction (including their ability to undertake their own analyses of what is going on) and to actively construct a satisfying professional identity.

\section{Preliminary results}

The results of the research project are being analysed to evaluate to what extent migrants' goals of acquiring socio-pragmatic competence in local ways of interacting are satisfactorily achieved through participating in the research-based instruction provided in the Workplace Communication course, and to assess to what extent these skills prove relevant once they enter a New Zealand workplace.

Results to date suggest a positive impact on socio-pragmatic development from both the in-class and workplace components of the Workplace Communication course. Initial analysis of the DCT and role play data, for example, shows migrants using increasingly sophisticated request strategies from pre-instruction, mid-point and final stage classroom data. Further development is also evident from the recordings at the workplaces themselves. Combined, these diverse data sources suggest significant development of pragmatic awareness and competence among the participants, with evidence of this being applied in practice in the workplace. The preliminary results 
thus suggest that explicit instruction using authentic input facilitates the development of pragmatic awareness and pragmatic proficiency in the workplace among EAL users.

\section{Future directions}

In addition to contributing to the further development of the Workplace Communication course to meet migrants' needs, the results of the current research project will be used by the LWP research team for further sociolinguistic analyses of workplace discourse, in particular the discourse of professional migrants in New Zealand workplaces. One potential focus of analysis will be the inherent tensions between the new migrants' desire to 'fit in' and obtain secure employment on the one hand, and their need to assert their expertise and construct a satisfying professional identity in a new environment on the other. The analysis will identify ways of improving the migrants' social 'fit', whilst also encouraging appreciation among their colleagues of migrants' sociolinguistic skills and diverse cultural resources.

The New Zealand government's Settlement Strategy focuses on settlement as a 'two-way commitment' whereby both newcomers and New Zealanders have a dual responsibility for achieving settlement outcomes. A future stage of the research project will allow for investigating the contribution of employers' expectations and attitudes to the extent of migrants' workplace communicative success. Interviews with employers will establish their expectations of employees and their attitudes towards EAL workers. The researchers will also explore the possibility of working with employers to provide socio-cultural information which may facilitate the development of greater understanding of their EAL employees. In these ways, the researchers hope to work with employers to raise their awareness of the positive attributes of migrants in professional workplaces and of the ways in which the cultural and linguistic resources they bring to a community of practice can enhance the quality of workplace interaction.

\section{Conclusion}

The research in progress described in this report is innovative in several respects with regard to research on language teaching. The current research project is the first of 
which we are aware to record authentic workplace talk in order to examine the effects for professional migrants of participation in a course which explicitly focuses on the development of socio-pragmatic skills in workplace interaction. Furthermore, we believe that the use of the LWP analysis to inform the Workplace Communication course, and the use of the LWP methodology and LWP analysis of migrants' workplace language to evaluate the effectiveness of the course, demonstrate a synergy between language teaching and language research that may prove useful worldwide. Even at its pilot stage, the current research project is already providing benefits for both the language teaching and language research environment at LALS.

\title{
Selection of work either published or 'in process'
}

\author{
Holmes, J., A. Joe, M. Marra, J. Newton, N. Riddiford \& B. Vine (fc). Applying
} linguistic research to real world problems: the case of the Wellington Language in the Workplace Project. In C. Candlin \& S. Sarangi (eds.), Handbook of Applied Linguistics (HAL) 3.

This article examines the value of using authentic data to develop teaching materials and considers the role of the linguist in addressing real world problems such as migrant unemployment. It demonstrates how linguists can work with lay-people to identify research areas of mutual interest and apply the results of this research in the wider community.

Newton, J. (2007). Adapting authentic workplace talk for workplace communication training. In H. Kotthoff and H. Spencer Oatey (eds.), Handbook of Intercultural Communication (Vol. 7). Berlin: Mouton de Grutyer: 519-535.

This article describes the challenge of selecting and adapting recordings of authentic workplace interactions collected by LWP for use in the Workplace Communication course. It discusses how, although the source interactions are largely intracultural, using this authentic language allows for identifying important socio-pragmatic features of workplace language that are rarely highlighted in artificial materials used 
in intercultural communication training, and provides participants with resources that are directly relevant to their needs.

Riddiford, N. (2007). Making requests appropriately in a second language: Does instruction help to develop pragmatic proficiency? The TESOLANZ Journal $15,88-102$.

This article explores the development of learners' production of requests in the Workplace Communication course. The results indicate that explicit instruction using authentic input facilitated the development of both pragmatic awareness and pragmatic proficiency.

Riddiford, N. and A. Joe (2005). Using authentic data in a workplace communication programme. New Zealand Studies in Applied Linguistics 11 (2), 103-110.

This research report describes the design of the Workplace Communication course, and its basis in authentic workplace interactions.

Julia de Bres and the Language in the Workplace Team (Janet Holmes, Angela Joe, Meredith Marra, Jonathan Newton, Nicky Riddiford and Bernadette Vine), School of Linguistics and Applied Language Studies, Victoria University of Wellington, PO Box 600, Wellington, New Zealand.

\footnotetext{
${ }^{1}$ In addition to the core team named earlier, LWP team members involved in the action research include Angela Joe (Director of the English Proficiency Programme at the English Language Institute), Nicky Riddiford (Course Coordinator, developer and principal teacher of the Workplace

Communication course) and Jonathan Newton (Senior Lecturer in Applied Linguistics). A wide range of community and voluntary partners are also involved.
} 